\title{
Somatic BRCA1 Gene Mutation
}

National Cancer Institute

\section{Source}

National Cancer Institute. Somatic BRCA1 Gene Mutation. NCI Thesaurus. Code C162184.

A change in the nucleotide sequence of the BRCA1 gene that originates in non-germline cells. 